\title{
Interplay of the Quality of Ciprofloxacin and Antibiotic Resistance in Developing Countries
}

\author{
Deepali Sharma ${ }^{1 \dagger}$, Rahul P. Patel ${ }^{1 *}$, Syed Tabish R. Zaidi', \\ Md. Moklesur Rahman Sarker', Qi Ying Lean ${ }^{3,4}$ and Long C. Ming ${ }^{1,5 *}$ \\ 'Pharmacy, School of Medicine, University of Tasmania, Hobart, TAS, Australia, ${ }^{2}$ Department of Pharmacy, State University \\ of Bangladesh, Dhaka, Bangladesh, ${ }^{3}$ Vector borne Diseases Research Group, Pharmaceutical and Life Sciences CoRe, \\ Universiti Teknologi MARA, Shah Alam, Malaysia, ${ }^{4}$ Faculty of Pharmacy, Universiti Teknologi MARA, Bertam, Malaysia, \\ ${ }^{5}$ School of Pharmacy, KPJ Healthcare University College, Negeri Sembilan, Malaysia
}

\section{OPEN ACCESS}

Edited by:

Xinhua Qu,

Shanghai Ninth People's Hospital,

China

Reviewed by:

Giulia Maria Camerino,

Università degli Studi di Bari Aldo

Moro, Italy

Leonardo Augusto Moraes,

National University of Singapore,

Singapore

${ }^{*}$ Correspondence:

Long C. Ming

ming.long@bath.edu

Rahul P. Patel

rahul.pate/@utas.edu.au

tThese authors have contributed equally to this work.

Specialty section: This article was submitted to Translational Pharmacology, a section of the journal

Frontiers in Pharmacology

Received: 03 April 2017 Accepted: 04 August 2017

Published: 21 August 2017

Citation:

Sharma D, Patel RP, Zaidi STR, Sarker MMR, Lean QY and Ming LC (2017) Interplay of the Quality of Ciprofloxacin and Antibiotic Resistance in Developing Countries.

Front. Pharmacol. 8:546.

doi: 10.3389/fphar.2017.00546
Ciprofloxacin, a second generation broad spectrum fluoroquinolone, is active against both Gram-positive and Gram-negative bacteria. Ciprofloxacin has a high oral bioavailability and a large volume of distribution. It is used for the treatment of a wide range of infections including urinary tract infections caused by susceptible bacteria. However, the availability and use of substandard and spurious quality of oral ciprofloxacin formulations in the developing countries has been thought to have contributed toward increased risk of treatment failure and bacterial resistance. Therefore, quality control and bioequivalence studies of the commercially available oral ciprofloxacin formulations should be monitored. Appropriate actions should be taken against offending manufacturers in order to prevent the sale of substandard and spurious quality of ciprofloxacin formulations.

Keywords: antibiotic resistance, ciprofloxacin, quality assurance, substandard drug, spurious drug, pharmacovigilence and drug monitoring, drug regulatory system, fluoroquinolones

\section{INTRODUCTION}

Antibiotics, from natural or synthetic sources, inhibit the growth of microorganisms or kill the bacteria (Barbereau, 2006; Nayyar et al., 2015; Reis et al., 2016). It is now evident that falsified and counterfeit medications can cause treatment failure and antibiotic resistance (World Health Organisation, 2016). According to the European Commission, falsified or fake medications are the ones that pass themselves off as real, authorized medications without being evaluated for their quality, safety and efficacy (European Commission, 2016). Such medications may contain substandard active ingredients, which are of low quality and/or have incorrect amount, either too high or too low (Lee et al., 2017). Counterfeit medications are, terminologically different from falsified medications. Counterfeit refers to medications that do not comply with regulation on intellectual and industrial property rights, for example, unregistered medicines sourced from parallel import (Fadlallah et al., 2016; European Medicines Agency, 2017). In developing countries including India, Pakistan, Bangladesh, Ethiopia, Nigeria, Kenya, Uganda, and Nigeria the control and monitoring of drug manufacturing, marketing, distribution, and consumption is not strictly controlled resulting in the availability of falsified medications. According to World Health Organisation, up to $10 \%$ of medications may be falsified worldwide. Of these, $50 \%$ are estimated to be antimicrobial agents of which $78 \%$ are from Asian and African countries (World Health Organisation, 2016). Among falsified antibiotics, $43 \%$ have no active ingredients, $24 \%$ are of bad 
quality, $21 \%$ are with less quantity of an active ingredient, and $7 \%$ are with wrong ingredients (Delepierre et al., 2012; Kratochwill et al., 2015). It was also found that the falsified antibiotics consisted of $50 \%$ of beta lactams, $12 \%$ quinolones, $11 \%$ macrolides, $7 \%$ cyclins, and $20 \%$ other antibiotics. India is reported as the leading country with the highest number of falsified antibiotics followed by Burma and Nigeria (Kelesidis and Falagas, 2015). More than 60,000 pharmaceutical formulations produced in India are not registered (Bhargava and Kalantri, 2013) and the availability of substandard antibiotics is increasing worldwide. This review mainly focuses on the availability of substandard formulations of generic ciprofloxacin, a type of quinolone, and its impact on bacterial resistance and treatment failure.

\section{Quinolones}

Quinolones are classified according to their generations (Drlica, 1999). Nalidixic acid, the first generation quinolone, is effective against Gram-negative bacteria excluding Pseudomonas species (von Rosenstiel and Adam, 1994). The structure of nalidixic acid is shown in Figure 1A. After intravenous administration, it is eliminated very rapidly and therefore sufficient systemic levels required for antibacterial effect cannot be achieved. Its plasma half-life is about one and half hour, and because of its rapid renal elimination, its use for the treatment of systemic infections was not possible (von Rosenstiel and Adam, 1994). However, it acted as an ideal urinary antiseptic, and, therefore, was used for the treatment of urinary tract infections. Emergence of bacterial resistance and high incidence of neurological, dermatological and gastrointestinal side effects eventually limited its use in clinical practice. Norfloxacin, ciprofloxacin, ofloxacin, enoxacin, and lomefloxacin are examples of second generation quinolones. Third generation quinolones include moxifloxacin, levofloxacin, gatifloxacin, and sparfloxacin. Trovafloxacin is an example of fourth generation quinolone (Neu, 1989).

Quinolones exert the potent antibacterial effect by binding to bacterial enzymes, DNA gyrase and topoisomerase IV. This binding results in the formation of quinolone-enzyme-DNA complex. Shortly after binding, the enzyme undergoes conformational changes. The enzyme breaks the DNA and the drug prevents religation of the broken DNA strands, thus preventing DNA replication. Ultimately, this results in the damage to bacterial DNA and thus cell death (Stefan et al., 2016). Unlike first generation, second generation quinolones are effective against Pseudomonas species, some Gram-positive bacteria (including Staphylococcus aureus but not Streptococcus pneumoniae) and some atypical pathogens. The antimicrobial spectrum of third generation quinolones is similar to that of second generation but they have extended Gram-positive and atypical microorganisms. Fourth generation quinolones are as effective as third generation quinolones against Gram-negative, Gram-positive and atypical pathogens but have broad anaerobic coverage (Symonds and Nix, 1992).

Quinolones have a good oral bioavailability (Drlica, 1999). Unlike most classes of antibiotics, the bioavailability of oral quinolones (except norfloxacin) is comparable to quinolones administered intravenously (Just, 1993; von Rosenstiel and
Adam, 1994). Therefore, often dose adjustment is not necessary while switching from intravenous to oral quinolones. The extent of absorption of orally administered quinolones is significantly decreased if co-administered with products containing positively charged cations such as zinc, aluminum, calcium, and magnesium. The positively charged cations form insoluble drug-cation complexes in the gastrointestinal tract (GIT). Quinolones have a large volume of distribution and their distribution in urinary tract and respiratory tissues is of important because they are effective against microorganisms commonly responsible for urinary tract and respiratory tract infections (Davis et al., 1996).

\section{Physicochemical and Pharmacokinetics Characteristic of Ciprofloxacin}

Ciprofloxacin, a second generation quinolone, has a $\mathrm{pH}$ dependent solubility (Jaman et al., 2015). It's solubility is maximum at $\mathrm{pH}$ below 5 and minimum near to the isoelectric point (pH 7) (Torniainen et al., 1996; Oishi et al., 2011). Besides, ciprofloxacin in zwitterionic form was found to be most sensitive to photodegradation at slightly basic $\mathrm{pH}$ (Torniainen et al.,

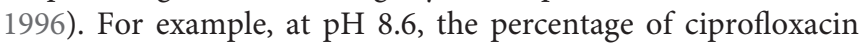
photodegradation is reported to be $85 \%$. On the other hand, the percentage of ciprofloxacin photodegradation decreases to $15 \%$ at $\mathrm{pH} 3.0$ and $\mathrm{pH} 4.0$ whereas the extent of photodegradation is similar at $\mathrm{pH} 6.0$ and $\mathrm{pH} 10.6$.

Ciprofloxacin is structurally similar to nalidixic acid (Figure 1B) (Davis et al., 1996). The sixth position controls the mechanism of action and bacterial potency of quinolones. Unlike nalidixic acid, ciprofloxacin contains the fluorine atom at position number 6 . Due to this single change, ciprofloxacin is approximately 100 times more potent than nalidixic acid. Positions 1 and 7 seven control the potency spectrum and pharmacokinetics of quinolones. $N$-ethyl and methyl groups present on the first and seventh position of nalidixic acid are replaced with a six-membered ring and $N$-cyclopropane respectively in ciprofloxacin resulting in ciprofloxacin's extended Gram-negative activity, higher potency, better tissue penetration, greater bioavailability, and longer plasma half-life (Sanchez et al., 1992; Tillotson, 1996). It is used for the treatment of a wide range of infections, such as complicated urinary tract infections, bone or joint infections, cystic fibrosis, prostatitis, typhoid, shigellosis, chronic suppurative otitis media, and epididymo-orchitis caused by susceptible bacteria. Common adverse drug reactions of ciprofloxacin include nausea, vomiting, diarrhea, and abdominal pain. Thrombophlebitis at intravenous infusion site, phototoxicity, transient hearing impairment, and crystalluria are some of the infrequent and rare reported adverse drug reactions of ciprofloxacin (Davis et al., 1996).

Following oral administration, ciprofloxacin is rapidly absorbed in the GIT by passive diffusion and reaches the peak serum concentration within $2 \mathrm{~h}$. The absorption rate is affected by intestinal $\mathrm{pH}$, with greater absorption in the duodenum and proximal jejunum than in the distal small intestine (Campoli-Richards et al., 1988; Davis et al., 1996). Ciprofloxacin demonstrates a concentration-dependent permeability and 

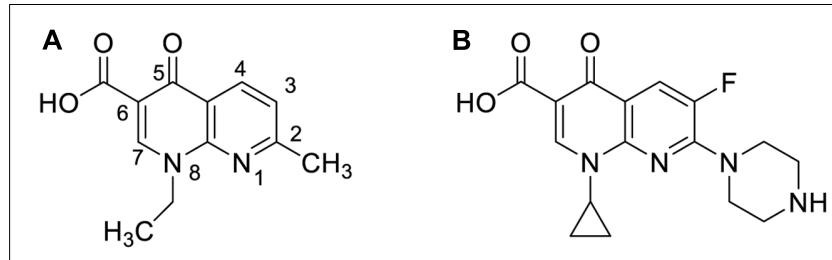

FIGURE 1 | Chemical structures of nalidixic acid (A) and ciprofloxacin (B).

it is widely distributed in body tissues and fluids including bile, prostatic tissues, gingival fluid, and lungs. Clearance of ciprofloxacin is by both renal and non-renal pathways (Micromedex, 2016). Approximately, two third of metabolites are excreted in the urine and 15\% in feces (Olivera et al., 2011).

\section{BIOAVAILABILITY AND BIOEQUIVALENCE OF INNOVATOR AND GENERIC CIPROFLOXACIN}

Generic equivalents of brand-name drugs (innovator drugs) have been introduced in the global healthcare market to lower the cost of medications (Kaushal et al., 2016). A generic drug product is assumed to be bioequivalent to the brand-name drug product (innovator drug serve as the reference) if there is no statistically significant difference in the rate and extent of absorption of the active ingredient when administered at similar dose (Turner, 2016). Comparative bioavailability studies need to be established before generic drug formulations are commercially available to consumers. This is to assure that the safety and efficacy of generic drug formulations are comparable to the corresponding innovator drugs (Oishi et al., 2011).

Several human studies comparing the bioequivalence of generic ciprofloxacin formulations to brand-name formulations have been reported before. The reported studies compared various pharmacokinetic parameters, such as extent of absorption [area under the curve (AUC)], maximum plasma concentration $\left(\mathrm{C}_{\max }\right)$, time to reach $\mathrm{C}_{\max }\left(\mathrm{T}_{\max }\right)$ and half-life, between generic and respective reference formulations. At three different oral doses $(250,500$, or $750 \mathrm{mg}$ ), pharmacokinetic parameters of generic formulations were equivalent to the reference formulations. As expected, a high dose of ciprofloxacin $(750 \mathrm{mg})$, often used in severe and/or complicated infections, showed higher $\mathrm{C}_{\max }$ than 500 and $250 \mathrm{mg}$ dose of ciprofloxacin. $\mathrm{T}_{\max }$ and half-live values after the administration of 750 and $250 \mathrm{mg}$ varied from 1.38 to $0.69 \mathrm{~h}$ and 4 to $5 \mathrm{~h}$, respectively (Plaisance et al., 1987). The oral bioequivalence of several ciprofloxacin formulations at different doses are presented in Table 1 (Azad et al., 2007; Hassan et al., 2007; Khan et al., 2009; Fahmy and Abu-Gharbieh, 2014). These studies reported that the rate and extent of absorption of the tested generic formulations are similar to those observed with brand-name formulations and therefore these generic and brand-name formulations could be used interchangeably (Azad et al., 2007; Valizadeh et al., 2012). However, 100s of ciprofloxacin generic formulations of ciprofloxacin are widely available worldwide. For example, there are more than 75 pharmaceutical companies in India that manufacture generic ciprofloxacin. Therefore, studies comparing the bioequivalence of such formulations to brand-name formulations are warranted.

\section{Bacterial Resistance to Ciprofloxacin}

Fluoroquinolone resistance occurs quickly and is related to molecular evolutionary biology and direct response toward drug pressure (Redgrave et al., 2014; Fasugba et al., 2015). The most common type of clinically significant resistance is alterations in the quinolone enzymatic targets, which is caused by specific mutation of gyrase and topoisomerase IV which in turn weakens the interactions between quinolones and bacterial enzymes (Aldred et al., 2014). Plasmid mediated resistance is another mechanism by which bacteria can acquire resistance to quinolones. It is proposed that bacteria acquire plasmid genes that code for proteins responsible for protecting bacterial enzymes, DNA gyrase and topoisomerase IV, from the effect of quinolones (van Hoek et al., 2011; Jacoby et al., 2014). Chromosome mediated resistance is developed due to under expression of porins or ever expression of cellular efflux pumps decreasing the cellular concentration of quinolones (Naeem et al., 2016; Turner, 2016).

Ciprofloxacin has been shown to be active against isolates of various Gram-positive and Gram-negative bacteria, both in vitro and in vivo (Tamma et al., 2012). It is one of the antibiotics used for respiratory, urinary tract, intestinal and abdominal infections caused by various pathogens including Escherichia coli, Haemophilus influenzae, other $H$. spp., Neisseria gonorrhoeae, N. meningitides, Moraxella catarrhalis, Klebsiella pneumoniae, Legionella pneumophila, Moraxella catarrhalis, Proteus mirabilis, and Pseudomonas aeruginosa, methicillin-susceptible Staphylococcus aureus, Streptococcus pneumoniae, Staphylococcus epidermidis, Enterococcus faecalis, and Streptococcus pyogenes (Rodriguez et al., 2009, 2015; Vesga et al., 2010; Agudelo and Vesga, 2012; Tamma et al., 2012). Nonetheless, concerns in relation to the appropriate use of fluoroquinolones and quality of their pharmaceutically equivalent formulations have been raised after the reported therapeutic failures of fluoroquinolones including ciprofloxacin when used for the treatment of various infections (Bowen et al., 2015; De Lappe et al., 2015; Kim et al., 2015). One of the main reasons for the reported treatment failure is thought to be due to increased bacterial resistance to fluoroquinolones (Jabeen et al., 2015).

Bacterial resistance to ciprofloxacin has been reported in the early 90 s and is continuously rising ever since (Cahana et al., 1995; Corti et al., 1995; Hakanen et al., 1999). For example, a study presented prevalence of ciprofloxacin among 480 isolates obtained from patients with urinary tract infections. The resistance rate to ciprofloxacin was $15.0 \%$. High resistance to ciprofloxacin was detected among Acinetobacter haemolyticus (28.6\%), Staphylococcus saprophyticus (25.0\%) (El Astal, 2005). Relatively recent systematic review and metaanalysis of observational studies concluded that the resistance 
TABLE 1 | Mean (range) pharmacokinetic parameters from a single dose of reference and test tablets of ciprofloxacin.

\begin{tabular}{|c|c|c|c|c|c|c|c|}
\hline $\begin{array}{l}\text { Name and } \\
\text { strength }\end{array}$ & $\begin{array}{l}\text { Number of healthy } \\
\text { volunteers }\end{array}$ & Type & $\begin{array}{c}A U C \infty \\
\left(\mathrm{mg} / \mathrm{L}^{*} \mathrm{~h}\right)\end{array}$ & Cmax (mg/L) & Half-life (h) & Tmax (h) & Reference \\
\hline $\begin{array}{l}\text { Ciproxin }{ }^{\circledR} \text { (Bayer } \\
\text { health care } \\
\text { pharmaceuticals); } \\
250 \text { mg }\end{array}$ & 24 adults & $\begin{array}{l}\text { Reference } \\
\text { formulation }\end{array}$ & $6.92(6.18-8.49)$ & $1.46(141-1.50)$ & $4.52(3.79-5.52)$ & $1.20(1.0-1.50)$ & Azad et al., 2007 \\
\hline $\begin{array}{l}\text { Quinox }^{\circledR} \text { (Eskayef } \\
\text { Bangladesh, Ltd.); } \\
250 \text { mg }\end{array}$ & & Test formulation & $6.67(6.18-8.48)$ & 1.49 (1.39-1.62) & $4.33(3.90-6.46)$ & $1.00(1.0-1.50)$ & \\
\hline $\begin{array}{l}\text { Ciproxin }^{\circledR} \text { (Bayer } \\
\text { Laboratory); } \\
500 \text { mg }\end{array}$ & 18 adults & $\begin{array}{l}\text { Reference } \\
\text { formulation }\end{array}$ & $11.95(7.96-19.51)$ & $2.16(1.19-3.23)$ & - & $1.56(1.0-2.5)$ & Morera et al., 2001 \\
\hline $\begin{array}{l}\text { Cinaflox }^{\circledR} \text { (Stein } \\
\text { laboratory); } 500 \text { mg }\end{array}$ & & Test formulation & $11.15(7.77-16.05)$ & $1.99(1.41-2.79)$ & - & $1.63(1.0-2.5)$ & \\
\hline $\begin{array}{l}\text { Ciprobay }{ }^{\oplus} \text { (Bayer } \\
\text { Vital GmbH and } \\
\text { Co., Germany); } \\
750 \text { mg }\end{array}$ & 24 adults & $\begin{array}{l}\text { Reference } \\
\text { formulation }\end{array}$ & $15.70(8.92-24.55)$ & $3.32(1.91-5.18)$ & $5.00(3.88-6.43)$ & $1.49(0.75-4)$ & Cuadrado et al., 2004 \\
\hline $\begin{array}{l}\text { Brand not } \\
\text { disclosed } \\
\text { (Dr. August Wolff } \\
\text { GmbH and Co., } \\
\text { Germany); } 750 \text { mg }\end{array}$ & & Test formulation & $15.31(8.92-22.51)$ & $3.50(2.12-5.15)$ & $5.06(3.95-6.31)$ & $1.38(0.75-2.5)$ & \\
\hline
\end{tabular}

rate of urinary E. coli to ciprofloxacin is increasing and the policy on appropriate use of ciprofloxacin should be developed and enforced especially in developing countries (Fasugba et al., 2015). Also, a study conducted in Brazil reported a much higher than expected rate of bacterial resistance to ciprofloxacin (Reis et al., 2016). Ciprofloxacin resistance varies significantly from country to country with the highest resistance reported in developing countries (Fasugba et al., 2015). Due to an increase in resistance, Infectious Diseases Society of America (IDSA) recommends to limit the use of fluoroquinolones to infections, where other antibiotics cannot be used due to reasons including associated side effects or causative organisms are found to be resistance to alternative antibiotics.

\section{Potential Reasons for Increased Bacterial Resistance to Ciprofloxacin}

There could be a number of reasons behind the observed increase in bacterial resistance to ciprofloxacin. One reason could be the overuse or misuse of ciprofloxacin likely to be due to wide spread availability of generic versions of ciprofloxacin. Overuse or misuse of antibiotics is known to promote bacterial resistance and is likely to limit the effectiveness of ciprofloxaxin. After the introduction of generic ciprofloxacin in the market, an increase in consumption of ciprofloxacin was observed. A study in Denmark showed that total consumption of oral ciprofloxacin increased significantly from 0.13 to 0.33 defined daily dose/1000 inhabitant-days. At the same time, the rate of ciprofloxacin resistance has increased by $200 \%$ (Jensen et al., 2010). In another study, it was reported that the resistance of isolated E. coli obtained from patients with UTI increased proportionally with the use of quinolones (Fasugba et al., 2015). Similarly, a wide spread use of ciprofloxacin was thought to be responsible for a significant rise in ciprofloxacin resistance over time (Fasugba et al., 2015). As the driving force for the prevalence of antibiotic resistance is the extent of drug use, there is a positive correlation between consumptions of quinolones and antibiotic resistance (Jensen et al., 2010). In certain parts of the densely populated developing countries such as Brazil, Indonesia, Pakistan, India and China, there are hot spots for emergence and spread of antibiotic resistance (Huynh et al., 2015). It was speculated that South Asia is the reservoir for the global spread of ciprofloxacin-resistant infections caused by various types of bacteria including $S$. saprophyticus, P. aeruginosa, $K$. pneumoniae, multidrug-resistant Salmonella enterica serotype Typhi/Paratyphi, E. coli, and Shigella sonnei (Rabaa et al., 2016). Mulder et al. (2016) reported that the use of two, three, or more prescriptions of fluoroquinolones during a single infection was associated with bacterial resistance to ciprofloxacin. Moreover, in certain parts of Africa, Asia and Middle East, the use of prescription drugs without medical advice is reported to be 100,58 , and $39 \%$, respectively. The frequent use of prescription drugs in such communities has contributed to increase bacterial resistance (Morgan et al., 2011).

Another reason for the observed increase in bacterial resistance to ciprofloxacin could be due to easy accessibility to substandard and spurious formulations of ciprofloxacin. Substandard and spurious generic versions of drugs are therapeutically ineffective when used clinically (Agudelo and Vesga, 2012). As a consequence, treatment fails and this potentially enhances the selection of bacterial resistance (Rodriguez et al., 2009). Weir et al. (2005) collected 130 ciprofloxacin eye drop samples sold in India and then randomly selected 30 samples for the analysis of ciprofloxacin concentration. The authors reported that in $20 \%$ samples, 
the concentration of ciprofloxacin was below the standard recommended range. In addition, a number of formulations had the concentration of ciprofloxacin sufficiently lower to have negative impact on clinical outcome leading to increased risk of bacterial resistance. Prazuck et al. (2002) collected three generic oral formulations of ciprofloxacin manufactured in India. The content of ciprofloxacin in two out of three formulations varied by more than $-20 \%$. One collected formulation in fact expired 11 months ago. This study highlighted the availability of poor quality of ciprofloxacin formulations in India. Previous studies have also shown that the production of substandard drugs is common in Southeast Asia (Newton et al., 2001). Bate et al. (2009) determined the quality of various antibiotics, including ciprofloxacin, commercially available in two major Indian cities; namely Chennai and Delhi. They collected 50 and 53 ciprofloxacin treatment packs from Delhi and Chennai pharmacies respectively. The quality was determined based on the content of ciprofloxacin and disintegration test. Approximately, $10 \%$ and $6 \%$ of ciprofloxacin collected from Delhi and Chennai, respectively failed either one or two quality tests. There could be a number of reasons behind the availability of substandard ciprofloxacin worldwide. However, one of the common reasons could be the lack of regulatory policies in relation to both appropriate manufacturing practice and quality assurance procedures.

\section{Way Forward}

Currently, approaches to determine bioavailability and bioequivalence of pharmaceutical products has been largely standardized. In United States, the sale of generic drugs is approved by Food and Drug Administration when they meet all the regulatory requirements provided in the Code of Federal Regulations (Kaushal et al., 2016). The regulatory environment of the country of marketing is important to assure the assessment of bioequivalence of drug products. WHO has made tremendous progress in developing international consensus for standardizing and harmonizing the regulatory requirement, mainly for manufacturing control, safety and efficacy of new drugs and assessing bioequivalence of generics. The national, regional organization and regulatory authorities of developing countries including Central Drugs Standard Control Organization (CDSCO), South African Development Community (SADC), and Association of South East Nations (ASEAN) should strive to provide comprehensive regulatory guidelines related to product quality testing and conduct of bioequivalence studies (Midha and McKay, 2009). Different

\section{REFERENCES}

Agudelo, M., and Vesga, O. (2012). Therapeutic equivalence requires pharmaceutical, pharmacokinetic, and pharmacodynamic identities: true bioequivalence of a generic product of intravenous metronidazole. Antimicrob. Agents Chemother. 56, 2659-2665. doi: 10.1128/AAC.06012-11

Aldred, K. J., Kerns, R. J., and Osheroff, N. (2014). Mechanism of quinolone action and resistance. Biochemistry 53, 1565-1574. doi: 10.1021/bi5000564 resources, expertise and stringent regulation and enforcement are required to ensure proper implementation to ensure generic formulations are safe and effective (Sarker et al., 2016). Moreover, post-marketing surveillance is also necessary as the use of higher strength drug than the labeled value can result in toxic effects due to overdose whereas taking substandard agents can result in treatment failure. Similarly, strict monitoring of the production of ciprofloxacin formulations by drug regulatory agencies as well as post-marketing quality control studies are required to prevent and identify the substandard and spurious brands of oral ciprofloxacin in order to prevent the risk of treatment failure and antibiotic resistance.

\section{CONCLUSION}

The substandard quality ciprofloxacin is potentially the driving force for ciprofloxacin resistance. The availability and use of substandard quality ciprofloxacin would jeorpadise the clincial efficacy of this broad spectrum antibitoic. Drug quality assurance and strict laws and regulations for manufacturing, importation, distribution, and sale of ciprofloxacin are required to prevent the availability and use of substandard ciprofloxacin formulations, which in turn will minimize the risk of treatment failure and antibiotic resistance. An international comprehensive policy for addressing the resistance of ciprofloxacin and other fluroquinonoles in general is much needed.

\section{AUTHOR CONTRIBUTIONS}

RP, SZ, and LM conceived the concept; DS, QL, RP, SZ, MS, and LM wrote the initial draft; DS, RP, SZ, MS, QL, and LM finalized the manuscript. All authors contributed toward revising the paper and agreed to be accountable for all aspects of the work.

\section{ACKNOWLEDGMENTS}

This work was supported by the Research Acculturation Grant Scheme (RAGS), Malaysia (RAGS/1/2014/SKK10/UITM/7). The authors would like to express their gratitude to the Ministry of Higher Education, Malaysia and Universiti Teknologi MARA, Malaysia for the financial support rendered for this research. The funders had no role in the study design, data collection and analysis, decision to publish, or preparation of the manuscript. 
Bhargava, A., and Kalantri, S. P. (2013). The crisis in access to essential medicines in India: key issues which call for action. Indian J. Med. Ethics 10, 86-95. doi: 10.20529/IJME.2013.028

Bowen, A., Hurd, J., Hoover, C., Khachadourian, Y., Traphagen, E., Harvey, E., et al. (2015). Importation and domestic transmission of Shigella sonnei resistant to ciprofloxacin-United States, May 2014-February 2015. Morb. Mortal. Wkly. Rep. 64, 318-320.

Cahana, Z., Gilboa, A., and Raz, R. (1995). Changes in susceptibility to ciprofloxacin in a community in northern Israel. Drugs 49(Suppl. 2), 173-174. doi: 10.2165/00003495-199500492-00030

Campoli-Richards, D. M., Monk, J. P., Price, A., Benfield, P., Todd, P. A., and Ward, A. (1988). Ciprofloxacin. A review of its antibacterial activity, pharmacokinetic properties and therapeutic use. Drugs 35, 373-447. doi: 10.2165/00003495-198835040-00003

Corti, G., Paradisi, F., Giganti, E., Buffini, G., Tortoli, E., Martelli, L., et al. (1995). Ciprofloxacin resistance in clinical isolates of Pseudomonas aeruginosa from Italian patients. Drugs 49(Suppl. 2), 175-176. doi: 10.2165/00003495199500492-00031

Cuadrado, A., Gascon, A. R., Solinis, M. A., Ramirez, E., Hernandez, R. M., Knie, U., et al. (2004). Bioequivalence of two oral ciprofloxacin tablets formulations. Int. J. Clin. Pharmacol. Ther. 42, 336-341. doi: 10.5414/CPP42336

Davis, R., Markham, A., and Balfour, J. A. (1996). Ciprofloxacin. An updated review of its pharmacology, therapeutic efficacy and tolerability. Drugs 51, 1019-1074. doi: 10.2165/00003495-199651060-00010

De Lappe, N., O'connor, J., Garvey, P., Mckeown, P., and Cormican, M. (2015). Ciprofloxacin-resistant Shigella sonnei associated with travel to India. Emerg. Infect. Dis. 21, 894-896. doi: 10.3201/eid2105.141184

Delepierre, A., Gayot, A., and Carpentier, A. (2012). Update on counterfeit antibiotics worldwide; public health risks. Med. Mal. Infect. 42, 247-255. doi: 10.1016/j.medmal.2012.04.007

Drlica, K. (1999). Mechanism of fluoroquinolone action. Curr. Opin. Microbiol. 2, 504-508. doi: 10.1016/S1369-5274(99)00008-9

El Astal, Z. (2005). Increasing ciprofloxacin resistance among prevalent urinary tract bacterial isolates in Gaza Strip, Palestine. J. Biomed. Biotechnol. 2005, 238-241. doi: 10.1155/JBB.2005.238

European Commission (2016). Falsified Medicines. Brussels: European Commission.

European Medicines Agency (2017). Falsified Medicines. Available at: http://www.ema.europa.eu/ema/index.jsp?curl=pages/special_topics/general/ general_content_000186.jsp [accessed March 21, 2017].

Fadlallah, R., El-Jardali, F., Annan, F., Azzam, H., and Akl, E. A. (2016). Strategies and systems-level interventions to combat or prevent drug counterfeiting: a systematic review of evidence beyond effectiveness. Pharm. Med. 30, 263-276. doi: 10.1007/s40290-016-0156-4

Fahmy, S., and Abu-Gharbieh, E. (2014). In vitro dissolution and in vivo bioavailability of six brands of ciprofloxacin tablets administered in rabbits and their pharmacokinetic modeling. Biomed Res. Int. 2014:590848. doi: 10.1155/ 2014/590848

Fasugba, O., Gardner, A., Mitchell, B. G., and Mnatzaganian, G. (2015). Ciprofloxacin resistance in community- and hospital-acquired Escherichia coli urinary tract infections: a systematic review and meta-analysis of observational studies. BMC Infect. Dis. 15:545. doi: 10.1186/s12879-015-1282-4

Hakanen, A., Siitonen, A., Kotilainen, P., and Huovinen, P. (1999). Increasing fluoroquinolone resistance in salmonella serotypes in Finland during 1995-1997. J. Antimicrob. Chemother. 43, 145-148. doi: 10.1093/jac/43.1.145

Hassan, Y., Alfadly, S. O., Azmin, M. N., Peh, K. K., Tan, T. F., Noorizan, A. A., et al. (2007). Bioequivalence evaluation of two different formulations of ciprofloxacin tablets in healthy volunteers. Singapore Med. J. 48, 819-823.

Huynh, B.-T., Padget, M., Garin, B., Herindrainy, P., Kermorvant-Duchemin, E., Watier, L., et al. (2015). Burden of bacterial resistance among neonatal infections in low income countries: how convincing is the epidemiological evidence? BMC Infect. Dis. 15:127. doi: 10.1186/s12879-015-0843-x

Jabeen, K., Shakoor, S., and Hasan, R. (2015). Fluoroquinolone-resistant tuberculosis: implications in settings with weak healthcare systems. Int. J. Infect. Dis. 32, 118-123. doi: 10.1016/j.ijid.2015.01.006

Jacoby, G. A., Strahilevitz, J., and Hooper, D. C. (2014). Plasmid-mediated quinolone resistance. Microbiol. Spectr. 2, 664-689. doi: 10.1128/microbiolspec. PLAS-0006-2013
Jaman, M., Chowdhury, A. A., Rana, A. A., Masum, S. M., Ferdous, T., Rashid, M. A., et al. (2015). In vitro evaluation of Ciprofloxacin Hydrochloride. Bangladesh J. Sci. Ind. Res. 50, 251-256. doi: 10.3329/bjsir.v50i4.25833

Jensen, U. S., Muller, A., Brandt, C. T., Frimodt-Møller, N., Hammerum, A. M., Monnet, D. L., et al. (2010). Effect of generics on price and consumption of ciprofloxacin in primary healthcare: the relationship to increasing resistance. J. Antimicrob. Chemother. 65, 1286-1291. doi: 10.1093/jac/dkq093

Just, P. M. (1993). Overview of the fluoroquinolone antibiotics. Pharmacotherapy 13, 4S-17S.

Kaushal, N., Singh, S. K., Gulati, M., Vaidya, Y., and Kaushik, M. (2016). Study of regulatory requirements for the conduct of bioequivalence studies in US, Europe, Canada, India, ASEAN and SADC countries: impact on generic drug substitution. J. Appl. Pharm. Sci. 6, 206-222. doi: 10.7324/JAPS.2016.60430

Kelesidis, T., and Falagas, M. E. (2015). Substandard/counterfeit antimicrobial drugs. Clin. Microbiol. Rev. 28, 443-464. doi: 10.1128/CMR.00072-14

Khan, M. K., Khan, M. F., Khan, H., and Mustafa, G. (2009). Bioavailability of ciprofloxacin tablets in humans and its correlation with the dissolution rates. Pak. J. Pharm. Sci. 22, 329-334.

Kim, J. S., Kim, J. J., Kim, S. J., Jeon, S. E., Seo, K. Y., Choi, J. K., et al. (2015). Outbreak of ciprofloxacin-resistant Shigella sonnei associated with travel to Vietnam, Republic of Korea. Emerg. Infect. Dis. 21, 1247-1250. doi: 10.3201/ eid2107.150363

Kratochwill, L., Powers, M., Mcgraw, M. A., King, L., O’neill, J. M., and Venkat, A. (2015). Factors associated with ciprofloxacin-resistant Escherichia coli urinary tract infections in discharged ED patients. Am. J. Emerg. Med. 33, 1473-1476. doi: 10.1016/j.ajem.2015.07.047

Lee, K. S., Yee, S. M., Patel, R. P., Razi Zaidi, S. T., Yang, Q., Al-Worafi, Y. M., et al. (2017). Combating sale of counterfeit and falsified medicines online: a losing battle. Front. Pharmacol. 8:268. doi: 10.3389/fphar.2017.00268

Micromedex (2016). “Drug monograph ciprofloxacin," in Micromedex (Ann Arbor, MI: Truven Health Analytics).

Midha, K. K., and McKay, G. (2009). Bioequivalence; its history, practice, and future. AAPS J. 11, 664-670. doi: 10.1208/s12248-009-9142-z

Morera, M., Cortés, J., Ramos, I., Moncada, J., and Fonseca, L. (2001). Bioequivalence of two oral ciprofloxacin formulations. Clin. Drug Investig. 21, 137-145. doi: 10.2165/00044011-200121020-00006

Morgan, D. J., Okeke, I. N., Laxminarayan, R., Perencevich, E. N., and Weisenberg, S. (2011). Non-prescription antimicrobial use worldwide: a systematic review. Lancet Infect. Dis. 11, 692-701. doi: 10.1016/S1473-3099(11) 70054-8

Mulder, M., Kiefte-De Jong, J. C., Goessens, W. H., De Visser, H., Hofman, A., Stricker, B. H., et al. (2016). Risk factors for resistance to ciprofloxacin in community-acquired urinary tract infections due to Escherichia coli in an elderly population. J. Antimicrob. Chemother. 72, 281-289. doi: 10.1093/jac/ dkw399

Naeem, A., Badshah, S. L., Muska, M., Ahmad, N., and Khan, K. (2016). The current case of quinolones: synthetic approaches and antibacterial activity. Molecules 21:268. doi: 10.3390/molecules21040268

Nayyar, G. M. L., Attaran, A., Clark, J. P., Culzoni, M. J., Fernandez, F. M., Herrington, J. E., et al. (2015). Responding to the pandemic of falsified medicines. Am. J. Trop. Med. Hyg. 92, 113-118. doi: 10.4269/ajtmh.14-0393

Neu, H. C. (1989). Chemical evolution of the fluoroquinolone antimicrobial agents. Am. J. Med. 87, 2S-9S.

Newton, P., Proux, S., Green, M., Smithuis, F., Rozendaal, J., Prakongpan, S., et al. (2001). Fake artesunate in Southeast Asia. Lancet 357, 1948-1950. doi: 10.1016/S0140-6736(00)05085-6

Oishi, T. S., Haque, M. A., Dewan, I., and Islam, S. A. (2011). Comparative in vitro dissolution study of some ciprofloxacin generic tablets under biowaiver conditions by RP-HPLC. Int. J. Pharm. Sci. Res. 2, 3129-3135.

Olivera, M. E., Manzo, R. H., Junginger, H. E., Midha, K. K., Shah, V. P., Stavchansky, S., et al. (2011). Biowaiver monographs for immediate release solid oral dosage forms: ciprofloxacin hydrochloride. J. Pharm. Sci. 100, 22-33. doi: 10.1002/jps.22259

Plaisance, K. I., Drusano, G. L., Forrest, A., Bustamante, C. I., and Standiford, H. C. (1987). Effect of dose size on bioavailability of ciprofloxacin. Antimicrob. Agents Chemother. 31, 956-958. doi: 10.1128/AAC.31.6.956

Prazuck, T., Falconi, I., Morineau, G., Bricard-Pacaud, V., Lecomte, A., and Ballereau, F. (2002). Quality control of antibiotics before the implementation 
of an STD program in Northern Myanmar. Sex. Transm. Dis. 29, 624-627. doi: 10.1097/00007435-200211000-00020

Rabaa, M. A., Thanh, D. P., De Lappe, N., Cormican, M., Valcanis, M., Howden, B. P., et al. (2016). South Asia as a reservoir for the global spread of ciprofloxacin-resistant Shigella sonnei: a cross-sectional study. PLoS Med. 13:e1002055. doi: 10.1371/journal.pmed.1002055

Redgrave, L. S., Sutton, S. B., Webber, M. A., and Piddock, L. J. (2014). Fluoroquinolone resistance: mechanisms, impact on bacteria, and role in evolutionary success. Trends Microbiol. 22, 438-445. doi: 10.1016/j.tim.2014. 04.007

Reis, A. C. C., Santos, S. R. S., Souza, S. C., Saldanha, M. G., Pitanga, T. N., and Oliveira, R. R. (2016). Ciprofloxacin resistance pattern among bacteria isolated from patients with community-acquired urinary tract infection. Rev. Inst. Med. Trop. Sao Paulo 58. doi: 10.1590/S1678-9946201658053

Rodriguez, C. A., Agudelo, M., Catano, J. C., Zuluaga, A. F., and Vesga, O. (2009). Potential therapeutic failure of generic vancomycin in a liver transplant patient with MRSA peritonitis and bacteremia. J. Infect. 59, 277-280. doi: 10.1016/j.jinf. 2009.08.005

Rodriguez, C. A., Agudelo, M., Zuluaga, A. F., and Vesga, O. (2015). Impact on resistance of the use of therapeutically equivalent generics: the case of ciprofloxacin. Antimicrob. Agents Chemother. 59, 53-58. doi: 10.1128/AAC. 03633- 14

Sanchez, J. P., Domagala, J. M., Heifetz, C. L., Priebe, S. R., Sesnie, J. A., and Trehan, A. K. (1992). Quinolone antibacterial agents. Synthesis and structure-activity relationships of a series of amino acid prodrugs of racemic and chiral 7-(3-amino-1-pyrrolidinyl)quinolones. Highly soluble quinolone prodrugs with in vivo pseudomonas activity. J. Med. Chem. 35, 1764-1773. doi: $10.1021 / \mathrm{jm} 00088 \mathrm{a} 011$

Sarker, M. M. R., Rashid, M. S., Raju, A. A., Rana, M., Karim, M. F. B., Akter, R., et al. (2016). Evaluation of the pharmaceutical quality of different brands of ranitidine tablets manufactured in Bangladesh: a pharmaceutical and public health prospective. J. Appl. Pharm. Sci. 6, 055-061. doi: 10.7324/JAPS.2016. 60109

Stefan, C. P., Koehler, J. W., and Minogue, T. D. (2016). Targeted nextgeneration sequencing for the detection of ciprofloxacin resistance markers using molecular inversion probes. Sci. Rep. 6:25904. doi: 10.1038/srep25904

Symonds, W. T., and Nix, D. E. (1992). Lomefloxacin and temafloxacin: two new fluoroquinolone antimicrobials. Clin. Pharm. 11, 753-766.

Tamma, P. D., Cosgrove, S. E., and Maragakis, L. L. (2012). Combination therapy for treatment of infections with gram-negative bacteria. Clin. Microbiol. Rev. 25, 450-470. doi: 10.1128/CMR.05041-11
Tillotson, G. S. (1996). Quinolones: structure-activity relationships and future predictions. J. Med. Microbiol. 44, 320-324. doi: 10.1099/00222615-445-320

Torniainen, K., Tammilehto, S., and Ulvi, V. (1996). The effect of $\mathrm{pH}$, buffer type and drug concentration on the photodegradation of ciprofloxacin. Int. J. Pharm. 132, 53-61. doi: 10.1016/0378-5173(95)04332-2

Turner, B. (2016). Ciprofloxacin resistance: a review of patients in East London undergoing prostate biopsy. Urol. Nurs. 36, 173-182.

Valizadeh, H., Hamishehkar, H., Ghanbarzadeh, S., Zabihian, N., and ZakeriMilani, P. (2012). Pharmacokinetics and bioequivalence evaluation of two brands of ciprofloxacin $500 \mathrm{mg}$ tablets in Iranian healthy volunteers. Arzneimittelforschung 62, 566-570. doi: 10.1055/s-0032-13 27571

van Hoek, A. H., Mevius, D., Guerra, B., Mullany, P., Roberts, A. P., and Aarts, H. J. (2011). Acquired antibiotic resistance genes: an overview. Front. Microbiol. 2:203. doi: 10.3389/fmicb.2011.00203

Vesga, O., Agudelo, M., Salazar, B. E., Rodriguez, C. A., and Zuluaga, A. F. (2010). Generic vancomycin products fail in vivo despite being pharmaceutical equivalents of the innovator. Antimicrob. Agents Chemother. 54, 3271-3279. doi: 10.1128/AAC.01044-09

von Rosenstiel, N., and Adam, D. (1994). Quinolone antibacterials. An update of their pharmacology and therapeutic use. Drugs 47, 872-901. doi: 10.1007/ BF03260131

Weir, R. E., Zaidi, F. H., Charteris, D. G., Bunce, C., Soltani, M., and Lovering, A. M. (2005). Variability in the content of Indian generic ciprofloxacin eye drops. $\mathrm{Br}$. J. Ophthalmol. 89, 1094-1096. doi: 10.1136/bjo.2004.059519

World Health Organisation (2016). Substandard, Spurious, Falsely Labelled, Falsified and Counterfeit (SSFFC) Medical Products. Available at: http://www. who.int/mediacentre/factsheets/fs275/en/ [accessed June 16, 2017].

Conflict of Interest Statement: The authors declare that the research was conducted in the absence of any commercial or financial relationships that could be construed as a potential conflict of interest.

Copyright (c) 2017 Sharma, Patel, Zaidi, Sarker, Lean and Ming. This is an openaccess article distributed under the terms of the Creative Commons Attribution License (CC BY). The use, distribution or reproduction in other forums is permitted, provided the original author(s) or licensor are credited and that the original publication in this journal is cited, in accordance with accepted academic practice. No use, distribution or reproduction is permitted which does not comply with these terms. 